\section{A Guide to the Literature of Chemistry}

By E. J. Crane, Austin M. Patterson and Prof. Eleanor B. Marr. Second edition. Pp. xv +397. (New York : John Wiley and Sons, Inc.; London : Chapman and Hall, Ltd., 1957.) 74s. net.

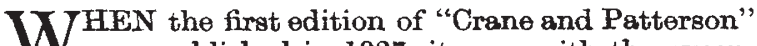
was published in 1927, it was, with the exception of the much slighter "Introduction to the Literature of Chemistry" of Dr. F. A. Mason, published three years earlier, essentially a pioneer work. It quickly met a recognized need and for a decade or more was unchallenged. If there are now other works that may meet the needs of British chemists more effectively, though probably not within two covers, that first edition also has given the names Crane and Patterson an honoured place in the literature of chemistry. It is no disparagement of the work that Prof. Marr and Dr. Crane have put into the preparation of what is virtually a new book to suggest that for British readers the second edition is unlikely to have the same appeal as the first: the changes arise out of the immense expansion of chemical literature, and considerations of space alone may well have dictated an appeal to the American chemist rather than to his British colleague.

The plan of the book is essentially unehanged and the chapter headings are unaltered, with the addition of new chapters on government publications and trade literature, but it is, as has been said, virtuslly a new book. Omission of the "Select List of Chemical Books" is the main change responsible for the reduction from 438 to 397 pages, and although it would have been impossible, within the limits of a single volume, to bring that list up to date, the book loses something of its appeal in consequence, and the first edition will retain some permanent value, particularly since in the treatment of historical literature the book is relatively weak. Criticism might be made on a few points of detail : for example, under biographical works, some help could have been given in tracing obitusry notices, the indexing of which, to say the least, is often fortuitous. Nevertheless, this second edition, like the first, displays the full scope of chemical literature and affords sound guidance to British and American chemists alike in handling a literature search.

R. Brightmain

Engineering Materials, Machine Tools and Processes By W. Steeds. Third edition. Pp. xi 426. (London and New York: Longmans, Green and Co., Ltd., 1957.) 35s. net.

TOURTEEN years have elapsed since the publica$\mathrm{H}$
tion of the second edition of this useful handbook of workshop practice. Various additions and alterations have been made to deal with newer processes and methods that have proved themselves during those years, and have increased the size of the book by twenty-five per cent. The pattern of the book is unchanged, except for a new chapter added at the end. This is entitled "Transfer Machines and Automation" and in only twenty-four pages deals with some of the ways in which mass production in machining processes can be made more automatic and handlingtime saved. Almost all of the other chapters have had changes ; some are merely minor changes of order and others are additions. In the chapter on ferrous materials reference is now made to isothermal transformation diagrams and hardenability, but the reference is probably too brief for the average reader to grasp fully the meaning of these topics. There are various additions to the non-ferrous alloys, including a page on titanium. This review is not the place to catalogue all the additions, but notable ones are the Merchant theory of chip formation and air gauging systems. A thorough revision of references has brought the book up to date and there are many improvements in the photographic illustrations.

\section{K. J. Pascoe}

\section{Theories of Nuclear Moments}

By R. J. Blin-Stoyle. (Oxford Library of the Physical Sciences, Vol. 1.) Pp. vi +89 . (London: Oxford University Press, 1957.) 8s. 6d. net.

THIS work is essentially a reprint of the valuable article by the author in Reviews of Modern Physics of January 1956, augmented by a chapter sketehing the experimental sources of information on nuclear moments, and an appendix on angular momentum states in quantum mechanics. To explain electromagnetic moments we should in principle start from the nuclear Hamiltonian and the form of the electromagnetic interaction. In fact, we have only rough ideas as to what these are, and even if they were known, accurate calculation would be very formidable. Thus the theory is at present at the stage of using obviously over-simplified models wherever they will work, the different models required being linked in only a very qualitative way. Anyone desiring a quick survey of this surprisingly successful process cannot do better than read the volume under review. The accounts of the various models and their applications are very brief, but an extensive biblio graphy allows details to be pursued in the original papers.

The reviewer would have welcomed some discussion of centre-of-mass effects. These appear explicitly only in connexion with the quadrupole moment of an odd-neutron nucleus on the single-particle model. The formula given corresponds to a classical treatment of core recoil, and the dubious nature of such a treatment is not mentioned.

It is to be hoped, of course, that the progress of research will in a few years render th's first edition obsolete. For this reason the use of paper covers, and the associated low price, are all the more commendable.

J. S. BELL

\section{The BBC Naturalist}

Edited by Desmond Hawkins. Pp. 96. (London : Rathbone Books, 1957.) 8s. 6d. net.

THE valuable part played by the B.B.C. in fostering the widespread and growing interest in British wild life is undoubtedly an important factor in helping to build up a large body of public opinion favourable to the idea of nature conservation. In such features as "The Naturalist", "Birds in Britain", and "Look", the B.B.C. has brought many naturalists of repute to the microphone or the television cemera, and the popularity of such programmes is something of a phenomenon in this technically minded age. The reviewer may be thought slightly cynical if he comments that many people quite incapable of recog. nizing a chaffinch on their doorstep may be perfectly familiar with the private life of a family of great black woodpeckers inside a tree-trunk in Germany, through the medium of television. Such an anomaly may be an unavoidable result of bringing natural history into the sphere of mass entertainment or mass education. However, recognition of the ephemeral nature of the spoken word has led to this excellent 